\title{
Inadequate Processing of Decellularized Dermal Matrix Reduces Cell Viability In Vitro and Increases Apoptosis and Acute Inflammation In Vivo
}

\author{
Aaron H. Morris, ${ }^{1,2}$ Julie Chang, and Themis R. Kyriakides ${ }^{1-3, *}$
}

\begin{abstract}
Decellularized tissue scaffolds are commonly used in the clinic because they can be used as substitutes for more traditional biomaterials, while imparting additional physiological effects. Nevertheless, reports of complications associated with their use are widespread and poorly understood. This study probes possible causes of these complications by examining cell viability and apoptosis in response to eluents from decellularized dermis. Using multiple sources of decellularized dermis, this study shows that typical decellularized scaffolds (prepared with commonly used laboratory techniques, as well as purchased from commercial sources) contain soluble components that are cytotoxic and that these components can be removed by extensive washes in cell culture media. In addition, this study demonstrates that these observed in vitro phenotypes correlate with increased apoptosis and acute inflammation when implanted subcutaneously in mice.
\end{abstract}

Key words: biomaterials; extracellular matrix; inflammation; tissue engineering

\section{Introduction}

Decellularized tissue scaffolds are frequently used in a variety of clinical applications such as chronic wound coverings, hernia repair, and heart valve replacements. ${ }^{1-3}$ The use of decellularized products has expanded rapidly because they can function as substitutes for traditional biomaterials (e.g., polyurethanes, PLGA, etc.) while offering the additional advantage of retaining native extracellular matrix (ECM) structure. Thus, they can serve as inductive scaffolds for cell invasion. In addition to their structural similarity to native tissue, decellularized scaffolds are effective because they can incorporate matrix-bound growth factors and other bioactive molecules that can be released upon degradation. ${ }^{4-6}$ Current commercially available decellularized biologic scaffolds are derived from several tissue sources, including skin, small intestinal submucosa, pericardium, and bladder.
Scaffolds are prepared in numerous ways, many of which are proprietary. Generally, decellularization methods fall into three broad categories: physical, chemical, and enzymatic. ${ }^{4-11}$ Most scaffolds are prepared using a combination of these methods, the most popular of which is chemical and enzymatic. ${ }^{8,12}$ Decellularization methods are tissue specific; for example, decellularization of thicker tissues often requires the perfusion of decellularization agents, rather than simple washes. Regardless of the decellularization method, the terminal steps almost always include extensive washing, usually with phosphate-buffered saline (PBS) or deionized water. Furthermore, scaffolds must either be decontaminated before decellularization and, subsequently, handled aseptically or terminally sterilized using ethylene oxide, ultraviolet irradiation, gamma irradiation, or supercritical carbon dioxide. ${ }^{8,13-16}$ Finally, the scaffolds are prepared for storage and shipment, which can

Departments of ${ }^{1}$ Biomedical Engineering, ${ }^{2}$ Vascular Biology and Therapeutics Program and ${ }^{3}$ Pathology, Yale University, New Haven, Connecticut.

*Address correspondence to: Themis R. Kyriakides, PhD, Department of Pathology, Yale University, New Haven, CT 06519, E-mail: themis.kyriakides@yale.edu

() Aaron H. Morris et al. 2016; Published by Mary Ann Liebert, Inc. This Open Access article is distributed under the terms of the Creative Commons License (http://creativecommons.org/licenses/by/4.0), which permits unrestricted use, distribution, and reproduction in any medium, provided the original work is properly credited. 
include packaging of hydrated matrix or lyophilizing to dry and preserve the matrix before packaging.

Techniques used to characterize prepared scaffolds include the following: histological stains to detect cellular and nuclear remnants, as well as to visualize ECM architecture; quantification of residual DNA and nuclear fragments; electron microscopy; mechanical testing; and other material characterization assays. ${ }^{9-12,17-19}$ Tests for material characterization often include direct cell contact on the material of interest or indirect assays in which the material of interest is incubated in cell media at a defined concentration-any soluble components of the material of interest are eluted into the media to create a liquid extract, which is in turn evaluated for effects on cultured cells. ${ }^{20-23}$ The effects of the eluent on cells can be examined using viability or proliferation assays, as well as various functional tests. Subsequent in vivo tests often include subcutaneous implantation to examine the in vivo toleration and host response to the material. ${ }^{18,24,25}$

Despite the aforementioned advantages of decellularized scaffolds, reports of complications are widespread. In many applications, including tissue expander breast reconstruction, use of decellularized biological scaffolds significantly increased the complication rate relative to the use of synthetic scaffolds. ${ }^{26-28}$ Common complications documented include infection, dehiscence, skin necrosis, and seroma; ${ }^{26-31}$ yet, the cause of these complications is currently unknown and has been difficult to determine. Generally, decellularized scaffolds are cytocompatible and exhibit a constructive reparative phenotype upon implantation. ${ }^{4,22}$ Investigations into ineffective decellularization techniques reveal that materials that contain significant residual DNA exhibit a pro-inflammatory response. ${ }^{31-33}$ In addition, a small, but growing, number of investigations have shown that decellularized scaffolds may have inhibitory effects on cell proliferation, or even exhibit cytotoxic effects. ${ }^{16,21,34-40}$ Investigators have attributed the causes of these negative effects to a variety of factors, such as residual detergents, residual sterilization chemicals, and alterations of matrix structure or biochemistry due to decellularization. ${ }^{16,35,37}$

Herein we investigated the cytocompatibility of decellularized scaffolds sourced from mouse skin decellularized with several methods and AlloDerm, a commercially available human dermis product. We used elution assays to study the response of keratinocytes and fibroblasts to these materials and investigated the cellular responses using metabolic viability and apopto- sis assays. Because of a paucity of data regarding the ideal mass of matrix necessary for these tests, we tested a range of soluble fraction dilutions. In addition, we examined the host response to these materials by subcutaneous implantation in mice. We demonstrate that acellular dermal materials can, at sufficiently high doses, lead to apoptosis both in vitro and in vivo, but that additional washes beyond the standard protocols mitigate this phenotype.

\section{Materials and Methods}

Isolation of murine skin

All procedures were performed in accordance with the regulations adopted by the National Institutes of Health and approved by the Animal Care and Use Committee of Yale University. Immediately following euthanasia, 12-14-week-old C57BL/6 mice were shaved and treated with depilatory cream for $1 \mathrm{~min}$ to remove remaining hair. Entire skins were subsequently harvested from the dorsum and flash frozen in liquid nitrogen. Frozen skins were stored at $-80^{\circ} \mathrm{C}$ until use.

\section{Decellularization with trypsin and Triton}

Frozen skins were thawed, and the epidermal side was gently scraped with a scalpel to remove the stratum corneum of murine skins. Skins were then treated with a protocol developed by Reing et al. for porcine skin. ${ }^{12}$ Briefly, skins were incubated for $6 \mathrm{~h}$ in $0.25 \%$ Trypsin-EDTA (J.T. Baker), followed by washes in $\mathrm{ddH}_{2} \mathrm{O}$ thrice for $15 \mathrm{~min}$. Skins were incubated in $70 \%$ ethanol for $12 \mathrm{~h}$ and 3\% $\mathrm{H}_{2} \mathrm{O}_{2}$ (Sigma) for $15 \mathrm{~min}$, followed by two 15min washes in $\mathrm{ddH}_{2} \mathrm{O}$. Skins were then incubated in $1 \%$ Triton X-100 (American Bioanalytical) in 0.26\% Tris (American Bioanalytical)/0.69\% EDTA (Sigma) for $6 \mathrm{~h}$ and then overnight. Finally, skins were washed in $\mathrm{ddH}_{2} \mathrm{O}$ six times for $15 \mathrm{~min}$ each. All above steps were performed at room temperature on an orbital shaker. Samples prepared in this manner will be referred to as d-TT (decellularized with trypsin and Triton). Skins receiving an extended wash were washed in serum-free Dulbecco's modified Eagle's medium (DMEM; Gibco) with $1 \%$ penicillin/streptomycin (Pen Strep; Gibco) on a rotating shaker at $37^{\circ} \mathrm{C}$ for $24 \mathrm{~h}$. These samples will be referred to as d-TT EW (decellularized with trypsin and Triton extended wash). Afterward, skins were lyophilized and stored in a desiccator until use. Samples of each skin were fixed, prepared for histological analysis, and then stained with hematoxylin and eosin using standard protocols. To grind decellularized skin, the lyophilized skin was cut into $1 \mathrm{~cm}$ wide strips and placed into 
the grinding chamber of a Porlex Mini Coffee Grinder (Amazon no. B0044ZA066) with the burr set to the finest grind. The skin was then ground until all of the skin became particulate matter. For scanning electron microscopy (SEM), the powder was adhered to carbon tape on top of an SEM stub. The powder was then chrome coated with $\sim 20 \mathrm{~nm}$ of chrome and imaged with a Hitachi SU-70 SEM.

\section{Decellularization with $\mathrm{NaOH}$}

To perform detergent-free decellularization, a previously published protocol was modified for use on mouse skin. ${ }^{41}$ Frozen skins were thawed and placed in $0.25 \%$ Trypsin-EDTA at $37^{\circ} \mathrm{C}$ for $90 \mathrm{~min}$. All subsequent steps were performed at room temperature on an orbital shaker. Skins were washed in $\mathrm{ddH}_{2} \mathrm{O}$ thrice for $15 \mathrm{~min}$ and then incubated in $0.1 \mathrm{M} \mathrm{NaOH}$ (Macron) for $16 \mathrm{~h}$. The skins were then washed in Dulbecco's phosphate-buffered saline (DPBS; Gibco) until the $\mathrm{pH}$ of the rinsing solution was neutral. If the skins received an extended wash, they were washed in serumfree DMEM with $1 \%$ pen strep on a rotating shaker at $37^{\circ} \mathrm{C}$ for $24 \mathrm{~h}$. Skins were lyophilized and stored in a desiccator until use. Samples of each skin were fixed and prepared for histological analysis and then stained with hematoxylin and eosin using standard protocols.

\section{Preparation of liquid extracts from matrix}

AlloDerm was a generous gift from Dr. Deepak Narayan (Department of Surgery, Yale University).

Liquid extracts were prepared using a method similar to those set by the International Organization for Standardization (ISO 10993-5:2009). It is important to note that many previously conducted extract cytotoxicity experiments only tested one concentration, but the ISO recommends testing a range of concentrations with an upper bound of $0.1 \mathrm{~g}$ material per $\mathrm{mL}$ of fluid. Many prior studies use $1 \mathrm{mg} / \mathrm{mL}$ of material or less and also do not study a range of concentrations. ${ }^{9,42-44}$ To perform a more comprehensive study, we prepared an extract by incubating $20 \mathrm{mg}$ of lyophilized ECM per $\mathrm{mL}$ of media, which was further diluted to generate a range of extracts (representing the soluble fraction from 0.25 to $10 \mathrm{mg} / \mathrm{mL}$ ). To prepare the original extract, a known mass of lyophilized matrix was sterilized by UV for $15 \mathrm{~min}$ and then added to serum-free DMEM with $1 \%$ pen strep to reach $20 \mathrm{mg} / \mathrm{mL}$. This incubation was performed on a rotating shaker at $37^{\circ} \mathrm{C}$ for $24 \mathrm{~h}$. Separate medium was prepared in parallel to serve both as the control and as the dilution medium for the original extracts. Dilutions of the original extract were performed to generate samples representing decreasing amounts of $\operatorname{ECM}(10,4,2,1$, 0.5 , and $0.25 \mathrm{mg} / \mathrm{mL}$ ). The extracts were then centrifuged at $2773 \mathrm{~g}$ for $10 \mathrm{~min}$ to remove any large particulate matter. Fetal bovine serum (FBS) was added to the media to a concentration of $10 \%$ FBS.

\section{Cell culture}

Mouse embryonic fibroblast cell line NIH3T3 (ATCC) was chosen as the model fibroblast cell line for the media extract experiments. Mouse keratinocyte cell line PAM212 was a generous gift from the laboratory of Dr. Gunter Wagner (Department of Ecology and Evolutionary Biology, Yale University). Cells were maintained in growth medium, DMEM, with $10 \%$ FBS and $1 \%$ pen strep.

\section{Extract viability assay}

Cells were harvested by addition of $0.25 \%$ Trypsin/ EDTA. A suspension of 5000 cells was added to each well of a 96-well plate and allowed to adhere overnight at $37^{\circ} \mathrm{C}$ and $5 \% \mathrm{CO}_{2}$. Media was then removed and replaced with extract medium, and the cells were incubated for $24 \mathrm{~h}$ at $37^{\circ} \mathrm{C}$ and $5 \% \mathrm{CO}_{2}$. Extract media was removed, replaced with normal growth media, and cell viability was determined using the CellTiter-Blue assay (Promega), according to manufacturer's instructions.

TUNEL assay

Cells were harvested by addition of $0.25 \%$ Trypsin/ EDTA. A suspension of 5000 cells was added to each well of a 96-well plate and allowed to adhere overnight at $37^{\circ} \mathrm{C}$ and $5 \% \mathrm{CO}_{2}$. Media was then removed and replaced with extract medium, and the cells were incubated for $1 \mathrm{~h}$ at $37^{\circ} \mathrm{C}$ and $5 \% \mathrm{CO}_{2}$. Cells were fixed for $1 \mathrm{~h}$ in $4 \%$ PFA (J.T. Baker). TUNEL staining was performed using the In Situ Cell Death Detection Kit, POD from Roche (catalog no. 11684817910), according to the manufacturer's instructions. The ConverterPOD was not used; instead, the cells were mounted with VECTASHIELD containing DAPI (Vector Labs) and imaged using fluorescence microscopy. The number of TUNEL-positive cells per high power field $(20 \times)$ was quantified using three fields per well. Three repeat experiments were performed $(n=3)$, and all experiments were analyzed by the same person.

\section{Subcutaneous implantation}

All procedures were performed in accordance with the regulations adopted by the National Institutes of Health 
and approved by the Animal Care and Use Committee of Yale University. Using a biopsy punch, $4 \mathrm{~mm}$ diameter implants were punched from lyophilized decellularized skins and then sterilized with UV irradiation. The thickness was determined by the original thickness of the mouse skin, but averaged $0.59 \mathrm{~mm}$. Subcutaneous implantations were performed as previously described. ${ }^{45} \mathrm{~A}$ total of eight C57BL/6 mice were used, four for each time point: 3 and 14 days. Each mouse received two subcutaneous implants in its dorsal region, one d-TT and one d-TT EW. Implants were excised en bloc upon termination of the study and prepared for histological analysis. Sections were stained with hematoxylin and eosin according to standard protocols. In addition, samples were analyzed by immunohistochemistry, with an antibody against macrophage antigen-3 (Mac-3) (BD Pharmingen), an antibody against mouse Ly-6B (a neutrophil marker; Serotec), and with a TUNEL assay (In Situ Cell Death Detection Kit, POD from Roche [catalog no. 11684817910]). The slides were imaged and the number of Ly-6B, Mac-3, or TUNEL-positive cells per high power field $(20 \times)$ was quantified using three fields per implant.

\section{Statistical analysis}

Data are expressed as the mean + the standard error of the mean. A two-tailed Student's $t$-test was used, and $p$-values $<0.05$ were considered statistically significant.

\section{Results}

Decellularization and processing

The aim of the d-TT decellularization process was to adequately remove cellular components while retaining the native dermal architecture of mouse skin. Although a similar process had previously been used to decellularize porcine skin, it has never been used on mouse skin to our knowledge. ${ }^{12}$ Decellularization resulted in adequate removal of cellular and nuclear material, which was clearly demonstrated by the lack of nuclear remnants on the hematoxylin and eosin stained tissue (Fig. 1B). d-TT and d-TT EW retained dermal structure similar to that observed in native skin (Fig. 1A-F). Subsequent grinding of the skin produced irregular particulate matter with diameters of $\sim 350 \mu \mathrm{m}$ (Fig. 1G, H).

Cytotoxicity testing of $d-T$ skin

Soluble components of the lyophilized ECM were extracted into serum-free DMEM supplemented with $1 \%$ pen strep. Serum was added to a final concentration of $10 \%$, and the resulting solutions were placed on ad- herent cells. With soluble fractions from $<2 \mathrm{mg}$ matrix/ $\mathrm{mL}$ media (similar to those that are frequently tested in the literature), either no effects or a slight increase in viable cells was observed with both NIH3T3 fibroblast cells and PAM212 keratinocytes. Interestingly, with increasing soluble fractions $(>4 \mathrm{mg} / \mathrm{mL}$ in the case of NIH3T3s or $20 \mathrm{mg} / \mathrm{mL}$ in PAM212s), significantly fewer viable cells were observed in the d-TT extracted medium (Fig. 2A). The effects of the particulate matrix were similar to those of the intact slabs (Supplementary Fig. S1). Boiling the material extracts or treating them with trypsin (before the addition of serum) did not mitigate the toxicity (Supplementary Fig. S2).

\section{Cytotoxicity testing of AlloDerm}

AlloDerm, a commercially available decellularized skin scaffold, was obtained and used as a point of comparison for the d-TT matrix. Material extract prepared from AlloDerm in sufficiently high doses also reduced the number of viable cells compared to control. NIH3T3 cells seemed more resistant to the effects of AlloDerm compared to the murine d-TT, with significantly fewer cells in only the 10 and $20 \mathrm{mg} / \mathrm{mL}$ groups. PAM212 cells were more sensitive to the AlloDerm extract compared to the murine d-TT, with significantly fewer cells even in the $0.5 \mathrm{mg} / \mathrm{mL}$ group. It is worth noting that the cell viability was well above $50 \%$ at concentrations below $20 \mathrm{mg} / \mathrm{mL}$ (Fig. 2B).

\section{Cytotoxicity testing of $\mathrm{d}-\mathrm{TT}$ EW}

Because the reduction in viability by matrix products in Figure 2 was observed with extracts produced by incubating them in media, we investigated whether washing the matrix in serum-free cell media at $37^{\circ} \mathrm{C}$ for $24 \mathrm{~h}$ would help mitigate the reduction in viability. When d-TT received this extended wash during its initial processing, it no longer had any negative effects on the viability of PAM212s and showed a slight, but significant, reduction in viability of the NIH3T3s in only the $20 \mathrm{mg} / \mathrm{mL}$ soluble fraction. Interestingly, the slight increase in PAM212 cell viability in the d-TT also disappeared with this extended wash (Fig. 3).

\section{Cytotoxicity testing of $\mathrm{NaOH}$ decellularized skins}

To address the possibility of residual detergents remaining in the decellularized matrix, another set of decellularized skins was prepared using $0.1 \mathrm{M} \mathrm{NaOH}$ as the decellularization reagent instead of the d-TT protocol. Upon buffering, $\mathrm{NaOH}$ should be rendered harmless such that any residual decellularization solution will 

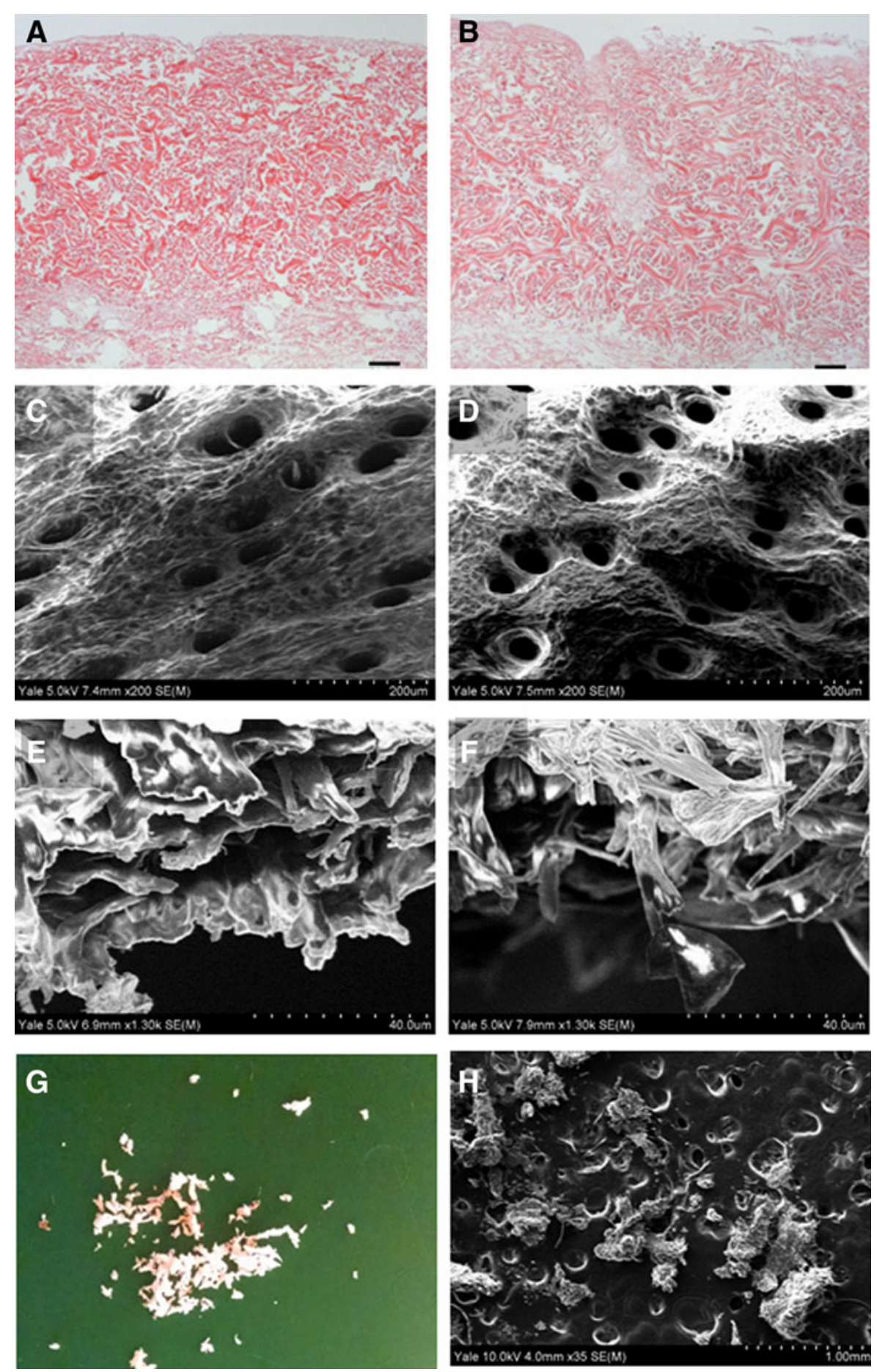

FIG. 1. H\&E of $d-T T(A)$ and $d-T T E W(B)$ indicating the absence of nuclear material in decellularized skin (scale bar is $50 \mu \mathrm{m}$ ). SEM micrographs of the epidermal side of $d-T T$ (C) and d-TT EW (D). SEM of the cross section of $d-T$ (E) and d-TT EW (F). Gross appearance of particulate $d-T$ skin after grinding (G) and SEM micrograph of the same $(\mathbf{H})$ indicating a particle diameter of $\sim 350 \mu \mathrm{m}$. d-TT, decellularized with trypsin and Triton; d-TT EW, decellularized with trypsin and Triton extended wash; H\&E, hematoxylin \& eosin. 


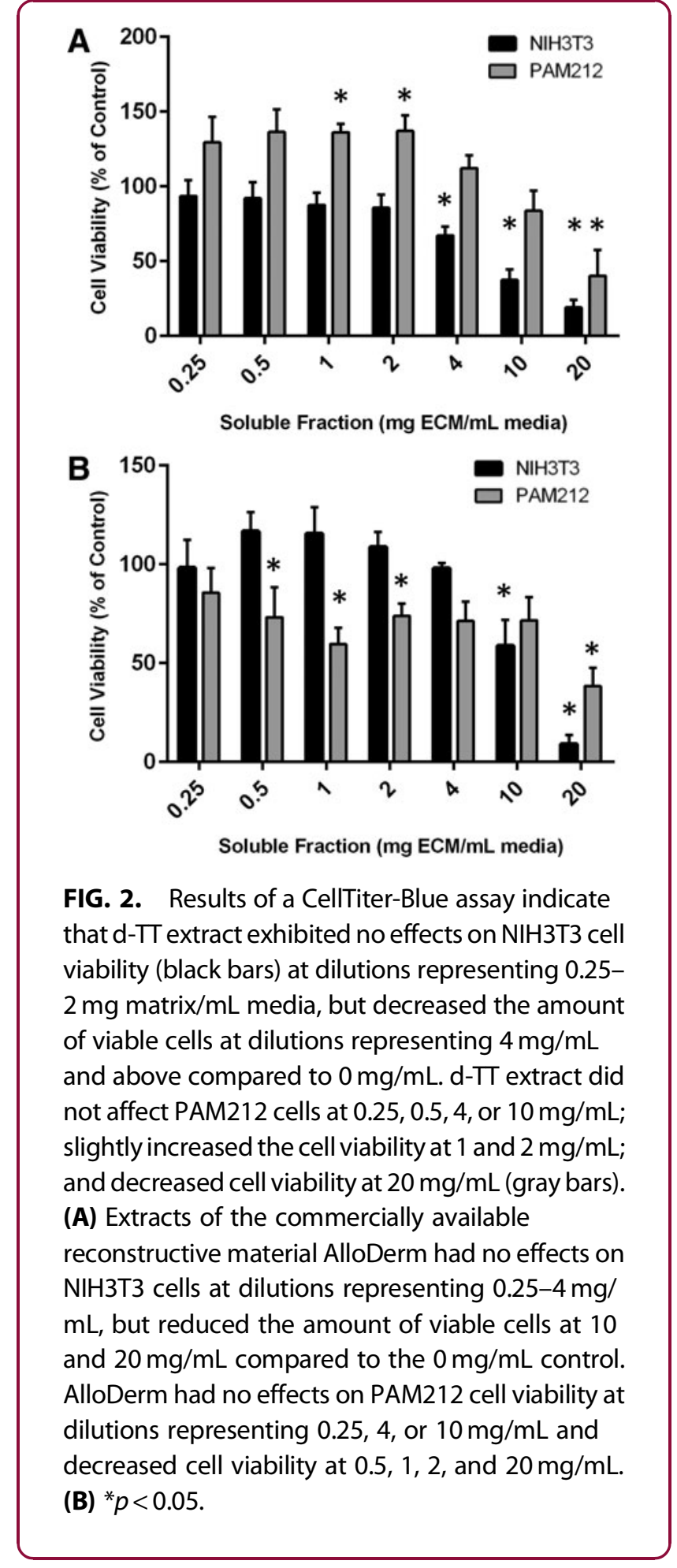

simply become salt. Similar to d-TT, $\mathrm{NaOH}$ decellularized skins significantly reduced viability of NIH3T3s at $20 \mathrm{mg} / \mathrm{mL}$. Moreover, an extended wash in media mitigated this effect (Fig. 4). This effect was not seen in PAM212 cells (Supplementary Fig. S3).

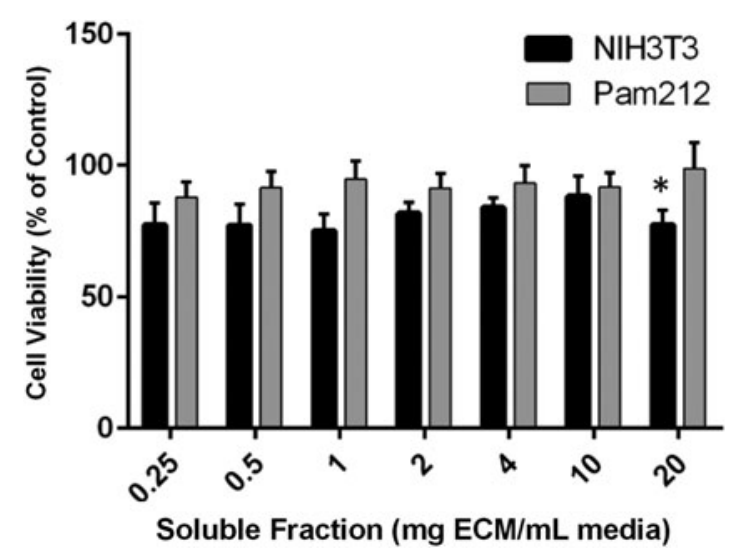

FIG. 3. Results of a CellTiter-Blue assay indicate that an extended wash of $\mathrm{d}-\mathrm{TT}$ skin at $37^{\circ} \mathrm{C}$ for $24 \mathrm{~h}$ rescued the negative effects that $d-T$ skin has on NIH3T3 (black bars) and PAM212 (gray bars) cells. With a soluble fraction prepared from $20 \mathrm{mg} / \mathrm{mL}$, the extract resulted in a slight, but significant reduction in the amount of viable NIH3T3s. ${ }^{*} p<0.05$.

\section{Apoptotic response to extracts}

To investigate the reduction in cell viability caused by the addition of ECM extracts, adherent NIH3T3 cells were treated with $20 \mathrm{mg} / \mathrm{mL}$ extracts for $1 \mathrm{~h}$ at $37^{\circ} \mathrm{C}$, fixed, and analyzed with the In Situ Cell Death

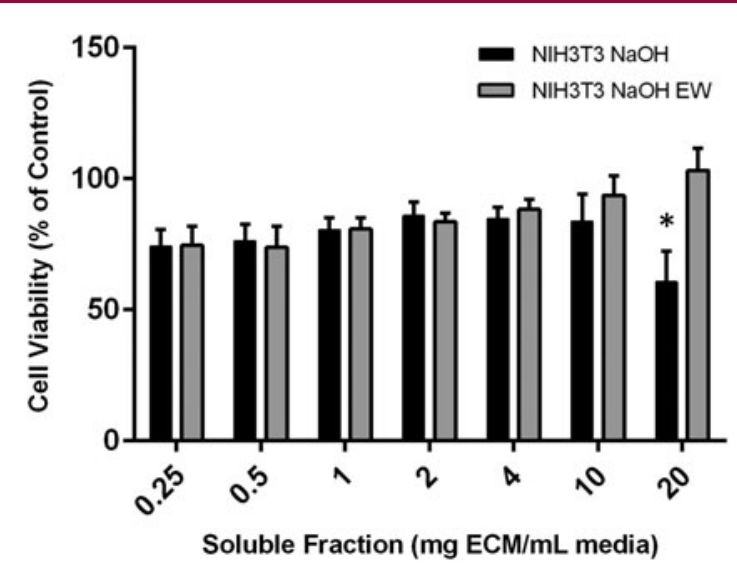

FIG. 4. Results of a CellTiter-Blue assay indicate that extracts of skin decellularized with $0.1 \mathrm{M}$ $\mathrm{NaOH}$ for $16 \mathrm{~h}$ significantly reduced the amount of viable NIH3T3 cells at $20 \mathrm{mg} / \mathrm{mL}$ (black bars), but that an extended wash of the decellularized skins at $37^{\circ} \mathrm{C}$ for $24 \mathrm{~h}$ rescued the phenotype (gray bars). ${ }^{*} p<0.05$. 

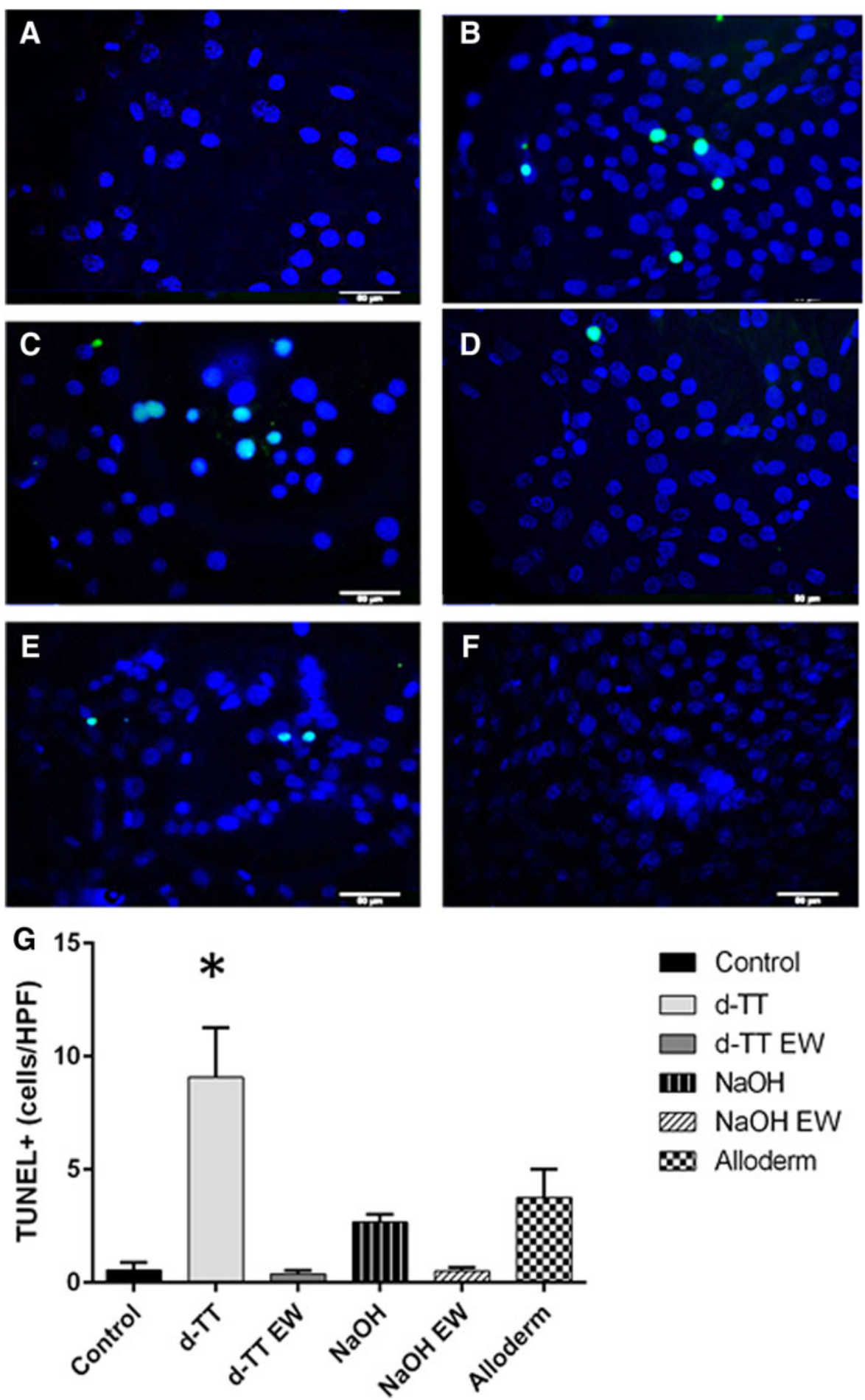

FIG. 5. TUNEL stain (green) and DAPI (blue) of NIH3T3 cells after a 1-h incubation in $20 \mathrm{mg} / \mathrm{mL}$ extracts from the following materials: untreated control (A), AlloDerm (B), d-TT (C), d-TT EW (D), NaOH decellularized skin (E), and $\mathrm{NaOH}$ decellularized EW (F) (scale bar is $50 \mu \mathrm{m}$ ). Quantification of the number of TUNEL-positive cells per HPF indicates that $\mathrm{d}$-TT extracts caused significantly more apoptosis at $1 \mathrm{~h}$ compared to control (G). ${ }^{*} p<0.05$. HPF, high power field. 
Detection Kit, POD from Roche. While apoptotic cells were observed in each material extract, d-TT induced more apoptosis (Fig. 5).

\section{In vivo implantation}

To determine any physiological effects of the observed extract toxicity, $4 \mathrm{~mm}$ disks of the lyophilized d-TT or d-TT EW materials were implanted subcutaneously in C57/BL6 mice for 3 and 14 days. Each mouse received two implants, one d-TT and one d-TT EW. Upon removal, each material was embedded and prepared for immunohistochemistry. H\&E staining showed no gross difference between d-TT and d-TT EW (Supplementary Fig. S4). Ly-6B staining for neutrophils showed increased neutrophil presence in the d-TT implants at day 3 compared to d-TT EW (Fig. 6); by day 14, the neutrophil presence was too low to quantify (data not shown). TUNEL staining showed more apoptotic cells around the implants in d-TT scaffolds compared to d-TT EW at day 3, while by day 14 there was no difference between the groups (Fig. 7A, B, E). In ad- dition, Mac-3 staining showed increased macrophage numbers around the d-TT implants at day 3 , but by day 14 there was no difference (Fig. 7C, D, F).

\section{Discussion}

This study investigated the cytocompatibility of materials derived from decellularized skin of murine and human origin. Routine extract cytotoxicity assays were the principle method used to study the materials because of their ubiquitous use among the biomaterial community. Interestingly, we found that mouse skin decellularized with techniques commonly used for porcine skin retained soluble factors that caused cytotoxicity in sufficiently high doses in a dose-dependent manner. ${ }^{12}$ These results were initially surprising because most reports of extract cytotoxicity testing of decellularized ECM materials reported no toxicity and often reported positive cellular effects. ${ }^{9,22,23}$ Nevertheless, upon closer examination of the literature, we discovered that there are a growing number of reports indicating that decellularized matrix materials inhibit proliferation, enhance

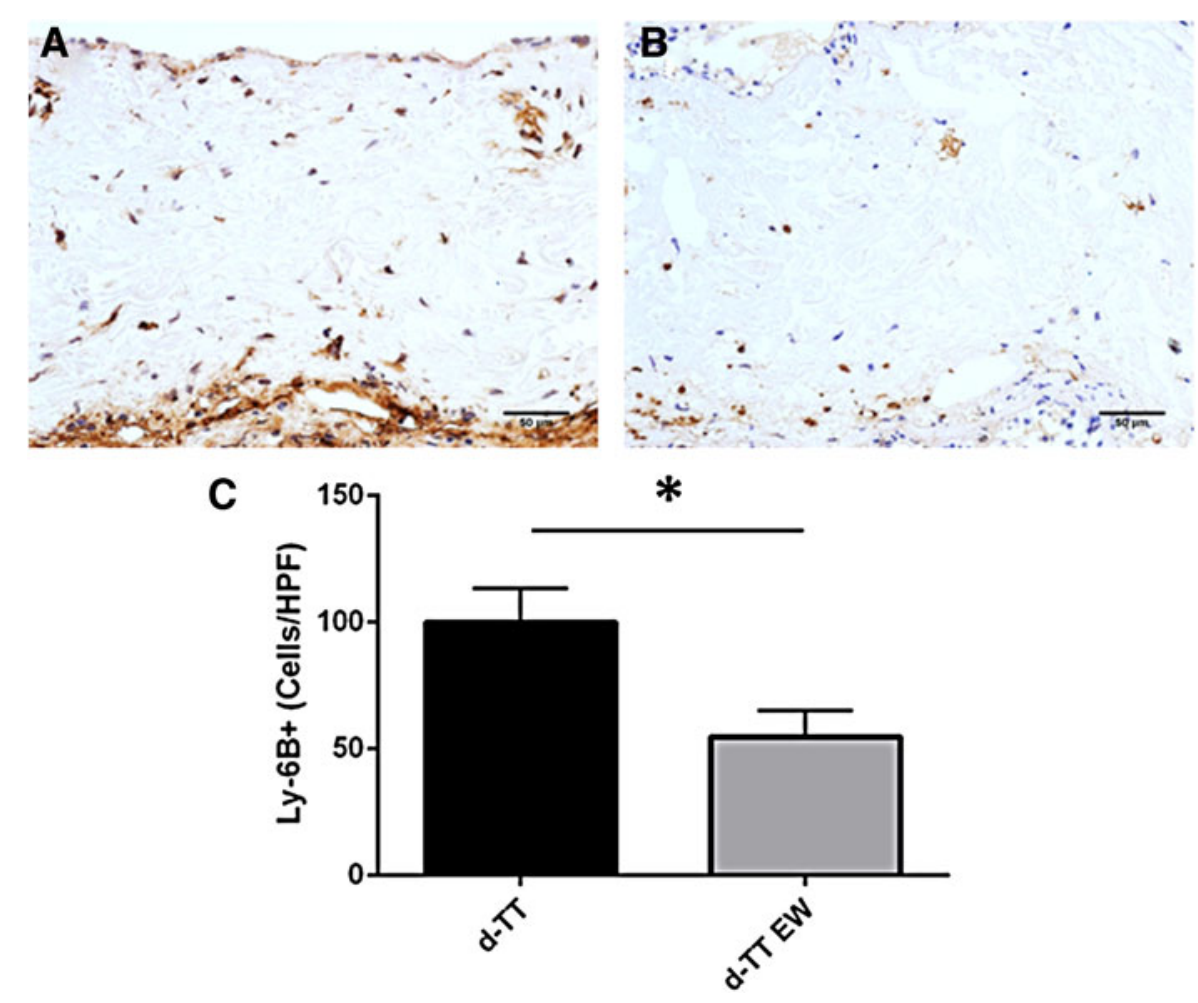

FIG. 6. Sample $d-T T$ (A) and $d-T$ EW (B) were implanted subcutaneously for 3 days before excision and immunohistochemical analysis. $d-T T$ showed increased Ly-6B-positive cells (neutrophils) compared to d-TT EW (scale bar is $50 \mu \mathrm{m}$ ). Quantification of staining (C) shows increases in Ly-6B in d-TT. ${ }^{*} p<0.05$. 

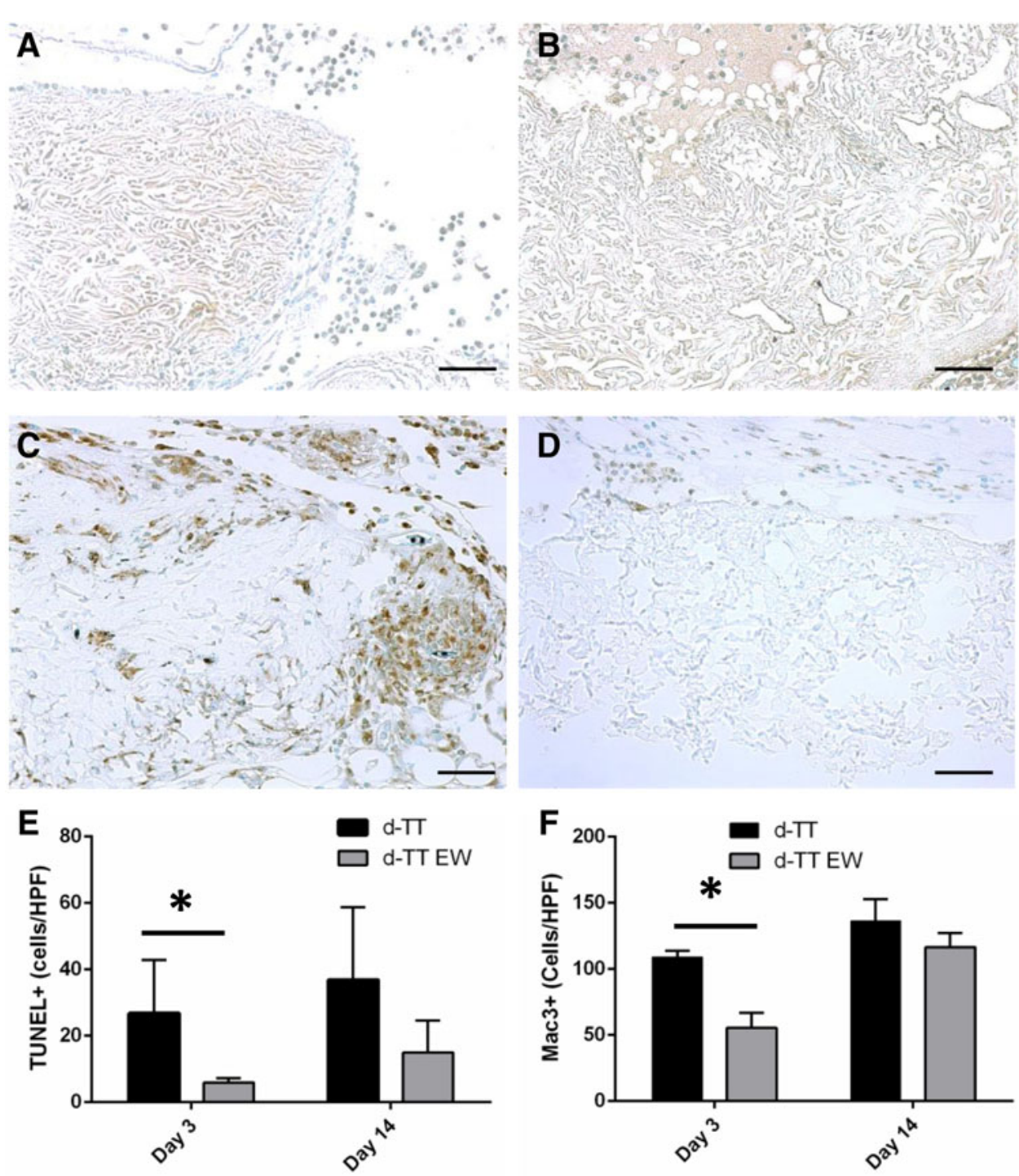

FIG. 7. Samples $d-T T(A, C)$ and $d-T T$ EW (B, D) were implanted subcutaneously for 3 (A-D) and 14 days before excision and immunohistochemical analysis. $d-T$ showed increased TUNEL-positive cells $(\mathbf{A})$ and Mac3-positive cells (C) at 3 days compared to d-TT EW (B, D, respectively) (scale bar is $50 \mu \mathrm{m}$ ). Quantification of TUNEL staining (E) and Mac-3 staining (F) shows increases in these stains in $d-T$ at day 3 , but no difference between groups at day $14 .{ }^{*} p<0.05$.

the apoptotic response, or even cause toxicity. ${ }^{16,21,34-40}$ We also observed that the soluble factors causing cytotoxicity were not rendered inert by boiling or treating the extract medium with trypsin.

Furthermore, we determined that AlloDerm caused similar dose-dependent toxicity. An additional washing step (in DMEM for $24 \mathrm{~h}$ at $37^{\circ} \mathrm{C}$ ) rescued the toxic effects of the scaffolds. The toxicity was most likely caused by residual detergent on the materials (despite lengthy washing procedures). To investigate this hypothesis, we decellularized skins with a detergent-free sodium hydroxide method. Because no detergents are used in this method, there cannot be any residual decellularization solutions upon the buffering of the base. Yet, the $\mathrm{NaOH}$ decellularized skins still exhibited a toxic effect on NIH3T3 cells. This effect was not as pronounced as that observed for d-TT decellularized skins or AlloDerm, but it remained nonetheless. Moreover, 
extended washing of the $\mathrm{NaOH}$ decellularized skins rescued the toxicity for these samples as well. This suggests that although residual detergents may play a role in the observed toxicity, they cannot be the only cause. We conclude that decellularized ECM contains other factors that cause cell toxicity. In fact, we determined that the d-TT skins induced apoptosis even at the early time point of $1 \mathrm{~h}$.

To investigate whether these observations correlate with complications in vivo, we implanted disks of lyophilized decellularized skins subcutaneously in mice for 3 and 14 days. We observed that the d-TT skins caused more apoptosis, as well as neutrophil and macrophage recruitment, compared to the d-TT EW at 3 days. This suggests that the soluble cytotoxic factors observed in these ECM materials in vitro lead to increased early apoptosis and acute inflammation in vivo. Because of the increasing number of reports of complications when using decellularized ECM materials in a surgical setting, these results could help us better understand the complicated host response to these materials. Further research into these materials and what is causing these effects is needed to create solutions for surgical complications.

\section{Acknowledgments}

This work was funded by National Institutes of Health Grants (GM-072194). This material is based upon work supported by the National Science Foundation Graduate Research Fellowship under Grant No. DGE-1122492 (A.H.M.). Any opinion, findings, and conclusions or recommendations expressed in this material are those of the authors and do not necessarily reflect the views of the National Science Foundation. The use of facilities was supported by YINQE and NSF MRSEC DMR 1119826.

\section{Author Disclosure Statement}

No competing financial interests exist.

\section{References}

1. Sclafani AP, Romo $T$, Jacono $A A$, et al. Evaluation of acellular dermal graft in sheet (AlloDerm) and injectable (Micronized AlloDerm) forms for soft tissue augmentation. Arch Facial Plast Surg. 2000;2:130-136.

2. $\mathrm{Xu} \mathrm{H}$, Wan $\mathrm{H}$, Sandor $\mathrm{M}$, et al. Host response to human acellular dermal matrix transplantation in a primate model of abdominal wall repair. Tissue Eng Part A. 2008;14:2009-2019.

3. Wilson GJ, Courtman DW, Klement P, et al. Acellular matrix-a biomaterials approach for coronary-artery bypass and heart-valve replacement. Ann Thorac Surg. 1995;60(2 Suppl):S353-S358.

4. Badylak SF. The extracellular matrix as a biologic scaffold material. Biomaterials. 2007;28:3587-3593.

5. Brown BN, Badylak SF. Extracellular matrix as an inductive scaffold for functional tissue reconstruction. Transl Res. 2014;163:268-285.
6. Morris $\mathrm{AH}$, Kyriakides TR. Matricellular proteins and biomaterials. Matrix Biol. 2014;37:183-191.

7. Gilbert TW, Sellaro TL, Badylak SF. Decellularization of tissues and organs. Biomaterials. 2006;27:3675-3683.

8. Keane TJ, Swinehart I, Badylak SF. Methods of tissue decellularization used for preparation of biologic scaffolds and in-vivo relevance. Methods. 2015;84:25-34.

9. Wilshaw S-P, Kearney JN, Fisher J, et al. Production of an acellular amniotic membrane matrix for use in tissue engineering. Tissue Eng. 2006;12:2117-2129.

10. Dahms SE, Piechota HJ, Dahiya R, et al. Composition and biomechanical properties of the bladder acellular matrix graft: comparative analysis in rat, pig and human. Br J Urol. 1998;82:411-419.

11. Schenke-Layland K, Vasilevski O, Opitz F, et al. Impact of decellularization of xenogeneic tissue on extracellular matrix integrity for tissue engineering of heart valves. J Struct Biol. 2003;143:201-208.

12. Reing JE, Brown BN, Daly KA, et al. The effects of processing methods upon mechanical and biologic properties of porcine dermal extracellular matrix scaffolds. Biomaterials. 2010;31:8626-8633.

13. Badylak SF, Freytes DO, Gilbert TW. Extracellular matrix as a biological scaffold material: structure and function. Acta Biomater. 2009;5:1-13.

14. Hodde J, Janis A, Ernst D, et al. Effects of sterilization on an extracellular matrix scaffold: part I. Composition and matrix architecture. J Mater Sci Mater Med. 2007;18:537-543.

15. Hodde J, Janis A, Hiles M. Effects of sterilization on an extracellular matrix scaffold: part II. Bioactivity and matrix interaction. J Mater Sci Mater Med. 2007; 18:545-550.

16. Kudryk VL, Scheidt MJ, McQuade MJ, et al. Toxic effect of ethylene-oxidesterilized freeze-dried bone allograft on human gingival fibroblasts. J Biomed Mater Res. 1992;26:1477-1488.

17. Schwarz S, Koerber L, Elsaesser AF, et al. Decellularized cartilage matrix as a novel biomatrix for cartilage tissue-engineering applications. Tissue Eng Part A. 2012;18:2195-2209.

18. Bondioli E, Fini M, Veronesi F, et al. Development and evaluation of a decellularized membrane from human dermis. J Tissue Eng Regen Med. 2014;8:325-336.

19. Liao J, Joyce EM, Sacks MS. Effects of decellularization on the mechanical and structural properties of the porcine aortic valve leaflet. Biomaterials. 2008;29:1065-1074.

20. Kulig KM, Luo X, Finkelstein EB, et al. Biologic properties of surgical scaffold materials derived from dermal ECM. Biomaterials. 2013;34:57765784.

21. Luo X, Kulig KM, Finkelstein EB, et al. In vitro evaluation of decellularized ECM-derived surgical scaffold biomaterials. J Biomed Mater Res B Appl Biomater. 2015 [Epub ahead of print]; DOI: 10.1002/jbm.b.33572.

22. Pariente JL, Kim BS, Atala A. In vitro biocompatibility assessment of naturally derived and synthetic biomaterials using normal human urothelial cells. J Biomed Mater Res. 2001;55:33-39.

23. Pariente J-L, Kim B-S, Atala A. In vitro biocompatibility evaluation of naturally derived and synthetic biomaterials using normal human bladder smooth muscle cells. J Urol. 2002;167:1867-1871.

24. Hogg P, Rooney P, Ingham E, et al. Development of a decellularised dermis. Cell Tissue Bank. 2013;14:465-474.

25. Eppley B. Revascularization of acellular human dermis (alloderm) in subcutaneous implantation. Aesthetic Surg J. 2000;20:291-295.

26. Brooke $S$, Mesa J, Uluer $M$, et al. Complications in tissue expander breast reconstruction. Ann Plast Surg. 2012;69:347-349.

27. Chun YS, Verma K, Rosen H, et al. Implant-based breast reconstruction using acellular dermal matrix and the risk of postoperative complications. Plast Reconstr Surg. 2010;125:429-436.

28. Zhao X, Wu X, Dong J, et al. A meta-analysis of postoperative complications of tissue expander/implant breast reconstruction using acellular dermal matrix. Aesthetic Plast Surg. 2015;39:892-901.

29. Bellows CF, Albo D, Berger DH, et al. Abdominal wall repair using human acellular dermis. Am J Surg. 2007;194:192-198.

30. Nguyen $M-D$, Chen $C$, Colakoğlu $S$, et al. Infectious complications leading to explantation in implant-based breast reconstruction with AlloDerm. Eplasty. 2010;10:e48.

31. Zheng MH, Chen J, Kirilak Y, et al. Porcine small intestine submucosa (SIS) is not an acellular collagenous matrix and contains porcine DNA: possible implications in human implantation. J Biomed Mater Res B Appl Biomater. 2005;73:61-67. 
32. Badylak SF, Gilbert TW. Immune response to biologic scaffold materials. Semin Immunol. 2008;20:109-116.

33. Keane TJ, Londono R, Turner NJ, et al. Consequences of ineffective decellularization of biologic scaffolds on the host response. Biomaterials. 2012;33:1771-1781.

34. Rieder E, Kasimir MT, Silberhumer G, et al. Decellularization protocols of porcine heart valves differ importantly in efficiency of cell removal and susceptibility of the matrix to recellularization with human vascular cells. J Thorac Cardiovasc Surg. 2004;127:399-405.

35. Andrée B, Bela K, Horvath T, et al. Successful re-endothelialization of a perfusable biological vascularized matrix (BioVaM) for the generation of 3D artificial cardiac tissue. Basic Res Cardiol. 2014;109:441.

36. Vitteková $M$, Dragúnnová J, Kabát $P$, et al. Cytotoxicity testing of scaffolds potentially suitable for the preparation of three-dimensional skin substitutes. Cell Tissue Bank. 2014:15:345-355.

37. Gratzer PF, Harrison RD, Woods T. Matrix alteration and not residual sodium dodecyl sulfate cytotoxicity affects the cellular repopulation of a decellularized matrix. Tissue Eng. 2006;12:2975-2983.

38. Cebotari S, Tudorache I, Jaekel T, et al. Detergent decellularization of heart valves for tissue engineering: toxicological effects of residual detergents on human endothelial cells. Artif Organs. 2010;34:206-210.

39. Wang $Q$, Zhang C, Zhang $L$, et al. The preparation and comparison of decellularized nerve scaffold of tissue engineering. J Biomed Mater Res A. 2014;102:4301-4308.

40. Feil G, Christ-Adler M, Maurer S, et al. Investigations of urothelial cells seeded on commercially available small intestine submucosa. Eur Urol. 2006:50:1330-1337.

41. Zhang $X$, Deng Z, Wang $H$, et al. Expansion and delivery of human fibroblasts on micronized acellular dermal matrix for skin regeneration. Biomaterials. 2009;30:2666-2674.

42. Mirsadraee S, Wilcox HE, Korossis SA, et al. Development and characterization of an acellular human pericardial matrix for tissue engineering. Tissue Eng. 2006;12:763-773.
43. Derham $\mathrm{C}$, Yow $\mathrm{H}$, Ingram J, et al. Tissue engineering small-diameter vascular grafts: preparation of a biocompatible porcine ureteric scaffold. Tissue Eng Part A. 2008;14:1871-1882.

44. Stapleton TW, Ingram J, Katta J, et al. Development and characterization of an acellular porcine medial meniscus for use in tissue engineering. Tissue Eng Part A. 2008;14:505-518.

45. Kyriakides TR, Leach KJ, Hoffman AS, et al. Mice that lack the angiogenesis inhibitor, thrombospondin 2, mount an altered foreign body reaction characterized by increased vascularity. Proc Natl Acad Sci U S A. 1999;96:4449-4454.

Cite this article as: Morris AH, Chang J, Kyriakides TR (2016) Inadequate processing of decellularized dermal matrix reduces cell viability in vitro and increases apoptosis and acute inflammation in vivo, BioResearch Open Access 5:1, 177-187, DOI: 10.1089/biores.2016.0021.

$\begin{aligned} & \text { Abbreviations Used } \\ & \text { DMEM }=\text { Dulbecco's modified Eagle's medium } \\ & \mathrm{d}-\mathrm{T}=\text { decellularized with trypsin and Triton } \\ & \mathrm{d}-\mathrm{TT} \mathrm{EW}=\text { decellularized with trypsin and Triton } \\ & \quad \text { extended wash } \\ & \mathrm{ECM}=\text { extracellular matrix } \\ & \mathrm{H \& E}=\text { hematoxylin \& eosin } \\ & \mathrm{PBS}=\text { phosphate-buffered saline } \\ & \mathrm{SEM}=\text { scanning electron microscopy }\end{aligned}$

\section{Publish in BioResearch Open Access}

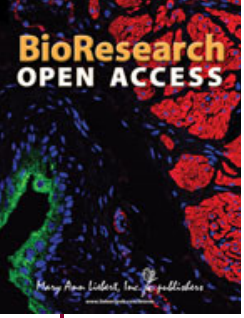

- Broad coverage of biomedical research - Immediate, unrestricted online access - Rigorous peer review

- Compliance with open access mandates - Authors retain copyright

- Highly indexed

- Targeted email marketing 